\title{
A comparison of focused and unfocused corrective feedback in Japanese EFL writing classes
}

\author{
Bradley D. F. Colpitts \& L'Shawn Howard \\ Kwansei Gakuin University \\ bradcolpitts@gmail.com, 1shawn77@gmail.com
}

\begin{abstract}
Bradley Colpitts \& L'Shawn Howard. A comparison of focused and unfocused corrective feedback in Japanese EFL writing classes. The Poznan Society for the Advancement of Arts and Sciences, PL ISSN 0079-4740, pp. 7-16

Though corrective feedback (CF) has generally been accepted as an effective means for improving student writing, some debate still exists as to whether focused (narrow) or unfocused (broad) CF is more effective in improving student writing in English as a Foreign Language (EFL) contexts. A comparative study was undertaken of two groups of high-proficiency Japanese and international students of English at one private university in the Kansai area of Japan. A third control group who did not partake in any corrective feedback were also used for comparison. Both groups of students wrote argumentative essays on a subject of their choosing over the course of eight weeks. The first group, Treatment Group A, was comprised of seven Japanese and non-Japanese university students $(n=7)$ who were trained in giving meta-linguistic (error coded), computermediated unfocused peer CF. The second group, Treatment Group B, was comprised of seven Japanese university students $(n=7)$ who were trained in giving meta-linguistic, computer-mediated focused feedback on five errors identified as being the most common in an initial diagnostic writing sample done in the first week. The initial draft, post-peer CF draft, post-teacher CF draft, and final draft were then analyzed. Students' ability to correctly resolve errors, and the number of errors per 100 words that emerged in each draft were then examined. The results suggest that unfocused peer and teacher CF may be a more effective means of reducing student errors in writing, possibly because it provides more overall learning opportunities.
\end{abstract}

Keywords: EFL, writing, corrective feedback, focused, unfocused

\section{Introduction}

Many L2 writing teachers at the tertiary level teach process writing, and process writing requires a certain focus on how to produce an effective written product. As a result, L2 writing teachers often focus on the organization, rhetorical style, and discourse transitions necessary to create an effective composition. These pedagogical approaches to teaching process writing have been accepted without much controversy. However, when it comes to language and mechanics, there has been much debate as to the efficacy of corrective feedback (CF) (Truscott 1996; Truscott \& Hsu 2008). Nevertheless, the expectation for and the appeal of written $\mathrm{CF}$ on student compositions remains. 
One explanation for the endurance of CF despite opposition to its use is the fact that L2 learners, unlike their L1 counterparts, have not fully internalized the grammar rules of the language in which they are writing. Therefore, they are unable to recognize malformed grammatical structures (Scovel 1998). This phenomenon compels many L2 writing teachers to consider form focused instruction in addition to teaching organization and other skills that are necessary to create an effective composition. Addressing the linguistic needs of L2 writing learners has been shown to be important to many writing teachers (Hyland 2003), and written corrective feedback is one approach that many teachers have used to address the issue. Moreover, L2 learners expect and highly value their teachers' written feedback, and many prefer their teachers to focus on their grammar errors (Hyland 2003).

In addition to meeting the needs and expectations of L2 writers, written corrective feedback has been shown to increase L2 writers' awareness of their grammatical errors; it promotes pushed output and allows the learner to externalize their language and test their hypotheses around certain grammatical structures (Swain 2008). It creates an opportunity for learners to notice their errors, and the process of correcting those errors has been shown to result in a decrease in the number of that same type of error in subsequent drafts (Kwon \& Lee 2011; Hosseiny 2014; Jokar \& Soyoof 2014; Ghazi \& Zamanian 2016; Seiffedin \& El-Sakka 2017). Furthermore, students develop a stronger ability to identify their own errors and those of their peers by taking part in this process (Colpitts 2016). It has also been argued that explicit knowledge of a grammatical structure can have an effect on a learner's implicit knowledge of the structure by making the features more salient to the learner (Ellis 2002). When learners engage in meaningful activities focusing on the linguistic features of their compositions, they engage in what Swain (2005) terms as languaging, and it allows them to make connections between conveying a meaningful message and the importance of grammatical accuracy.

Although there have been many studies on the efficacy of written $\mathrm{CF}$, there has been a lack of clear evidence in favour of one form of written CF over another, the following study was designed to address some of the ambiguities in the literature. This is particularly true of the East Asian EFL context. To this end, the present study aimed to answer the following questions:

1. Will focused or unfocused peer and teacher CF result in better uptake among Japanese EFL students?

2. What other insights might emerge from conducting a comparative study of these two teaching techniques?

\section{Review of the literature}

Studies that have examined the effect of corrective feedback on student writing feature a variety of different approaches, forms, and types of feedback ranging from explicit and implicit, to the use of metalinguistic codes, as well as focused and unfocused feedback. In addition to the type of feedback, studies have been done to determine L2 learners' perceptions of instructor feedback in contrast to that of peer feedback, and the effect of 
peer CF on the accuracy of L2 students' writing. In Fazilatfar et al. (2014), two groups of students from an advanced writing course were compared to determine the effect of unfocused $\mathrm{CF}$ on the syntactic and lexical complexity of their writing on subsequent drafts. The results of the study showed that the group that received unfocused CF outperformed the control group which did not receive any feedback on their drafts. Many studies compared different forms of feedback and will be discussed in further detail in the next section.

\subsection{Studies on comparing types of written corrective feedback}

The studies discussed below that compare different types of CF fall into three categories: those that compare focused and unfocused; those that compare direct and indirect; and those that compare metalinguistic feedback with recasts. A common theme among these different studies is the apparent effectiveness of focused CF over that of unfocused, as well as the efficacy of metalinguistic feedback. A study conducted by Seiffedin \& El-Sakka (2017) examined the effect of CF on L2 student drafts. The researchers found that indirect metalinguistic $\mathrm{CF}$, as well as direct written $\mathrm{CF}$, led to fewer errors on subsequent drafts of students that received indirect metalinguistic CF than those of the control group which did not receive any feedback. Ellis et al. (2008) examined narratives to determine whether or not focused or unfocused CF had an effect on the accurate use of definite and indefinite articles. The results showed that focused CF had the greatest effect on improving students' use of articles in narrative writing.

Frear \& Chiu (2015) looked at the effects of focused and unfocused indirect CF on the accuracy of the use of past tense in new pieces of writing, and found that focused indirect $\mathrm{CF}$ was more effective than unfocused $\mathrm{CF}$. Comparing direct and indirect $\mathrm{CF}$, Hosseiny (2014) separated participants into three groups, one group received direct CF, the other group received indirect $\mathrm{CF}$, while the control group did not receive any feedback. Using TOEFL tests to determine whether or not either treatment resulted in improved accuracy in L2 writing, Hosseiny (2014) found that both experimental groups outperformed the control group and there was no significant difference between the two experimental groups. In a case study of two Iranian English language learners, Jokar \& Soyoof (2014) found that the student who received explicit CF demonstrated greater retention of the grammatical structures than the student who received implicit CF. Kwon \& Lee (2011) analyzed a series of text chats in which participants received indirect CF in the form of recast, explicit correction, metalinguistic feedback, clarification, translation, repetition, and elicitation from both their peers and instructor. During the chat sessions, the instructor and a peer would respond to an error either by recast, elicitation, clarification, or repetition. Analysis of the data showed that recast was the most frequent form of feedback, and metalinguistic feedback had the highest rate of uptake, but it resulted in the lowest rate of self-correction. Repetition and elicitation resulted in the most attempts of students to self-correct. The results of the study suggest that indirect CF can be effective for uptake, but that direct feedback might be needed for students who do not pay attention to form but rather focus on the meaning of text. It should also be 
noted that the context of this study is that of a text-based synchronous computer mediated communication and therefore is closer to the conditions characteristic of a conversation rather than a composition which has different expectations and may require different cognitive processes. However, the types of feedback, particularly the students' reaction to peer feedback, offers an interesting perspective on $\mathrm{CF}$ in a less traditional context.

\subsection{Studies on peer written corrective feedback}

The merits of peer corrective feedback have been demonstrated in a number of studies. In the aforementioned study by Kwon \& Lee (2011), peer CF yielded different results and took on a different form than the instructor CF. The type of correction also seemed to differ from that of the instructor, and in some cases, the learners invented a different method of correction when offering explicit correction. Participants also expressed a positive attitude toward receiving peer feedback regardless of their attitude toward their own grammatical competence (Kwon \& Lee 2011). This positive attitude toward receiving peer CF was also found in Kazemipour (2014), in which the effects of two types of CF on students' final exams on the performance of students in the subsequent semester were examined. The results of the study found that the learners valued their peers' feedback over the instructor's feedback. This might be because unlike many studies comparing instructor and peer $\mathrm{CF}$, the participants in this study did not provide feedback on each other's exams. Instead, they worked in groups to correct the errors found by the instructor. Similar to the sentiment of the students in the Kazemipour (2014) study, the participants in a study examining the perceptions of two different forms of feedback (instructor and peer) demonstrated a preference for giving feedback especially with regards to noticing grammatical errors in their own writing (Colpitts 2016). However, when receiving feedback, the students preferred their instructor's feedback.

In a study on the effect of peer $\mathrm{CF}$, self-CF, and instructor $\mathrm{CF}$ on the accurate use of lexical errors and pronoun agreement in student essays, the origin of $\mathrm{CF}$ seemed to influence the number of lexical errors and errors with pronoun agreement in the different experimental groups (Diab 2016). Interestingly, there was no significant difference between the peer CF and the instructor CF, but those students who engaged in self-CF had a greater decrease in errors than those who received peer or instructor feedback (Diab 2016). Peer feedback when paired with instructor feedback and in Diab's study self-CF lends a deeper dimension to the process of CF. Peers offer new perspectives on how to correct errors, and it provides an opportunity for learners to think critically about their grammatical accuracy, and increases their ability to notice their errors more readily.

\section{Methodology}

This study was conducted over the course of eight weeks during the spring semester of 2017. The participants were two classes of high-proficiency, EFL learners in the same 
advanced academic writing course. Treatment Group A was initially comprised of nine students, two males and seven females. Both male students failed to complete the writing composition (and thus the course), leaving a sample of seven students $(n=7)$. Five of the students were native-Japanese speakers, one was a Chinese exchange student to Japan, and one was a Japanese student who had grown up in Mexico with one Mexican parent, whose first language was Spanish. Treatment Group B was initially comprised of nine students, but two of the students were unable to complete the peer review phase of the treatment, so the compositions of only seven students $(n=7)$ were considered. All seven of the students were native-Japanese speakers, five were females and two were males. To determine the effect of each of the treatments and the origins of feedback, data from a control group was also used. In terms of proficiency levels and age, the control group was similar to the two treatment groups, and it was comprised of four males and three females $(n=7)$. Two of the females were non-native Japanese speakers, one was from Taiwan, and the other was from Finland.

The students in the treatment groups were assigned a short, 250 or more word composition project in their first class on one of five topics from which they could choose. These compositions aimed to establish a clearer picture of the students' initial writing proficiency, and provide a basis for the instructor of Treatment Group B to choose items for focused corrective feedback.

Both classes underwent a period of peer corrective feedback training. They were given a list of codes to provide one another with metacognitive peer $\mathrm{CF}$, and engaged in some cooperative peer $\mathrm{CF}$ activities in class to develop their capacity in this regard. Treatment Group A, which formed the unfocused peer CF treatment group, was provided with a set of nine codes to identify mistakes in their classmates' writing: SP (spelling), V (vocabulary), T (tense), G (grammar), WO (word order), ME (meaning), PF (punctuation/formatting), $\wedge$ (missing word), and ? (another mistake). Treatment Group B was given a list of five codes: SV (subject verb agreement), \# (singular/plural), T (verb tense mistake), $\mathrm{P}$ (pronoun agreement), and $\wedge$ (missing word; usually an article). The control group did not receive any corrective feedback regarding lexical or grammatical errors.

The efficacy of both treatments was compared first using a model proposed by Storch \& Wigglesworth (2010). Using this framework, student uptake was examined; that is, their ability to correctly resolve the errors identified by their peers and instructors. In this study, uptake refers to any action taken by the student in subsequent drafts to change the error identified by the peer or instructor. This concept originated from Lyster \& Ranta (1997: 49), in which the learner's reaction to the teacher's feedback on an error is defined as uptake. In the case of this study, the uptake is indicated by reformulations of the error in subsequent drafts. Any reformulation, deletion, or reordering of words or phrases that occurred in response to peer or teacher corrective feedback was considered a single reformulation. The total number of feedback items was calculated, and the number of correct and incorrect reformulations, as well as items that went unchanged were also counted.

As this left some ambiguity as to the efficacy of the treatments, a second comparison was undertaken using the model put forth by Chandler (2003: 273), which involves dividing the total number of errors by the total number of words and multiplying the re- 
sulting amount by 100 . This was done to measure which treatment resulted in more accurate writing. Using the formula provided by Chandler (2003), the same instructor/ researcher scanned the first and final drafts of the control group as well as the two treatment groups for the total number of errors. The errors were marked according to the error types delineated in the focused and unfocused corrective feedback procedures. They were as follows: singular-plural, vocabulary, spelling, meaning, subject-verb agreement, missing word, tense, grammar, word order, and pronoun agreement. The results were then tallied, and the number of errors per 100 words of text was determined. The data from the treatment groups were digital, so the total number of words was determined by the "Word Count" tool provided by Microsoft Word and Google Docs. The word count for the control group, however, was determined by an estimation of 250 words per page multiplied by the number of pages. The results of both processes are examined in greater detail below.

\section{Results}

\subsection{Students ability to correctly resolve errors}

Using the aforementioned model proposed by Storch \& Wigglesworth (2010), the total number of errors identified by both treatment groups was tallied and of those we calculated the number of errors which were correctly or incorrectly resolved, or left unresolved. Each category was also calculated as a percentage of the total number of errors identified rounded to the nearest first decimal. The results of this analysis can be found in Table 1.

Table 1: Comparison of uptake between treatment groups

Peer Corrective Feedback

\begin{tabular}{lcccc}
\hline & Identified & Correctly Resolved & Incorrectly Resolved & Unresolved \\
\hline $\begin{array}{l}\text { Treatment Group A } \\
\text { (Unfocused) }\end{array}$ & $126(100 \%)$ & $88(69.8 \%)$ & $16(12.7 \%)$ & $23(18.3 \%)$ \\
$\begin{array}{l}\text { Treatment Group } \\
\text { B (Focused) }\end{array}$ & $35(100 \%)$ & $29(82.9 \%)$ & $0(0 \%)$ & $6(12.7 \%)$ \\
\hline
\end{tabular}

Instructor Corrective Feedback

\begin{tabular}{lcccc}
\hline & Identified & Correctly Resolved & Incorrectly Resolved & Unresolved \\
\hline $\begin{array}{l}\text { Treatment Group A } \\
\text { (Unfocused) }\end{array}$ & $250(100 \%)$ & $189(75.6 \%)$ & $47(18.8 \%)$ & $14(5.6 \%)$ \\
\hline $\begin{array}{l}\text { Treatment Group } \\
\text { B (Focused) }\end{array}$ & $152(100 \%)$ & $100(65.8 \%)$ & $10(6.6 \%)$ & $42(27.6 \%)$ \\
\hline
\end{tabular}


In the case of peer $\mathrm{CF}$, there appeared to be a significantly higher success rate among the focused group, though they identified far fewer errors at 35, as compared to 126 among the unfocused treatment. Of the 35 errors identified by the focused group, $29(82.9 \%)$ were correctly resolved, six (17.1\%) were unresolved, and none were incorrectly resolved. In the unfocused group, on the other hand, of the 126 errors identified, $88(69.8 \%)$ were correctly resolved, $16(12.7 \%)$ were incorrectly resolved, and $23(18.3 \%)$ were left unresolved. As students had fewer overall errors to resolve, and less variety of error types, these results could be expected.

With instructor corrective feedback however, the numbers offered a more convoluted answer. As with peer CF, the unfocused treatment provided more opportunity for error identification in type, thus the total number of errors was considerably higher at 250 errors, than with the focused group at 152 . While there were again fewer incorrectly resolved errors at $6.6 \%$ as compared to $18.8 \%$ among the unfocused group, there was a much higher number of unresolved errors at $27.6 \%$ as compared to the focused CF group at $5.6 \%$. This means on the whole, the unfocused group had more success at correctly resolving the errors identified by their instructor at $75.6 \%$ than the focused group at $65.8 \%$. This occurred despite the greater total number of errors identified, and a wider variety of error types.

\subsection{Errors per 100 words}

The results of the Chandler (2003) measure of errors per 100 words are detailed in Table 2 in both the first and final drafts in the control group, while Tables 3 and 4 illustrate those of treatment groups A and B. To maintain their anonymity, each individual student is represented by a number followed by the letter that corresponds to the type of group; for example, the first student in the control group is labeled as $1 \mathrm{C}$, and the first student in treatment group $\mathrm{A}$ is labeled $1 \mathrm{~A}$ etc.

Table 2: Total number of errors per 100 words of text for the control group

\begin{tabular}{ccc}
\hline Student & First draft & Final draft \\
\hline 1C & 3.8 & 2.1 \\
2C & 7.6 & 6.8 \\
3C & 8.1 & 11.4 \\
4C & 18.4 & 14.1 \\
$5 \mathrm{C}$ & 12.6 & 9.6 \\
$6 \mathrm{C}$ & 5.6 & 4.7 \\
$7 \mathrm{C}$ & 10.0 & 7.2 \\
\hline Average & 9.4 & 8.0 \\
\hline
\end{tabular}


Table 3: Total number of errors per 100 words of text for the treatment group A

\begin{tabular}{ccc}
\hline Student & First draft & Final draft \\
\hline $1 \mathrm{~A}$ & 3.1 & 1.0 \\
$2 \mathrm{~A}$ & 3.4 & 1.1 \\
$3 \mathrm{~A}$ & 3.5 & 1.1 \\
$4 \mathrm{~A}$ & 1.4 & 1.1 \\
$5 \mathrm{~A}$ & 3.6 & 2.1 \\
$6 \mathrm{~A}$ & 3.5 & 1.4 \\
$7 \mathrm{~A}$ & 1.9 & 2.1 \\
\hline Average & 2.9 & 1.4 \\
\hline
\end{tabular}

Table 4: Total number of errors per 100 words of text for treatment group B

\begin{tabular}{ccc}
\hline Student & First draft & Final draft \\
\hline 1B & 7.6 & 5.7 \\
2B & 8.0 & 5.2 \\
3B & 6.0 & 2.7 \\
4B & 5.5 & 5.2 \\
5B & 5.6 & 3.3 \\
6B & 7.3 & 4.3 \\
7B & 5.9 & 2.2 \\
\hline Average & 6.6 & 4.1 \\
\hline
\end{tabular}

It would appear that the unfocused corrective feedback was the most effective treatment, most notable is the decrease in errors per 100 words of text between the first and final drafts with an average of 2.9 errors per 100 words to an average of 1.4 errors per 100 words. Instructor unfocused corrective feedback appears to have resulted in a greater decrease in errors per 100 words than peer corrective feedback. Both treatment groups outperformed the control group in terms of errors per 100 words on the final drafts. However, with the exception of $3 \mathrm{C}$ and $7 \mathrm{~A}$ whose number of errors increased in the final draft, all three groups showed a reduction in errors per 100 words on each subsequent draft, which would suggest that the process of revising the same paper might have raised the students' awareness of lexical errors in each subsequent draft resulting in fewer errors in each draft. At the same time, both focused and unfocused corrective feedback appear to yield better results in reducing the number of errors in each draft in contrast to the drafts that did not receive any corrective feedback. This could indicate that all things being relatively equal among the three groups, unfocused instructor cor- 
rective feedback appears to be the most effective method for improving student writing accuracy.

\section{Discussion and implications}

Revisiting the research questions for this study, it can be determined that for this group unfocused CF from the instructor is the most effective method not only for learner uptake, but also for the reduction of number of errors per 100 words of text. Students in the focused treatment group saw greater success at correctly resolving peer CF than with the unfocused group. It could be theorized that this is because the errors identified by peers were simpler, surface-level mistakes. However, the unfocused group's ability to more accurately resolve errors identified by their instructor may indicate that deeper learning has taken place through the unfocused treatment, perhaps due to the fact that the greater number of errors identified provided more learning opportunities. The comparison of errors per 100 words appears to validate this argument, both when comparing the efficacy of peer CF on the whole as compared to the control group, and when comparing the efficacy of the two CF styles.

This study also contributes to the findings of previous studies (Ellis et al. 2008; Frear \& Chiu 2015) that have found both focused and unfocused corrective feedback to have pedagogical value. This study illustrates how second language writing students have benefited and could continue to benefit from unfocused corrective feedback as well as focused corrective feedback to a lesser extent, and that there are merits to implementing or continuing to utilize these teaching methods.

\section{Limitations}

The study discussed in this paper is limited by both a small sample size, and contextual matters related to EFL education in Japan. The students who participated in this study were highly motivated and came into their classes with a higher than average English proficiency level. Thus, similar results might not be possible in all teaching contexts, though a larger-scale study could help in proving or disproving this notion. Upon conclusion of the study and gathering of the data, the researchers noted the limitation presented by not having included a qualitative component. Including some form of qualitative inquiry may have elicited affective factors that impacted on either treatment group, as well as students' own theories as to the efficacy of the interventions undertaken. In previous studies, such as with Chandler (2003), reading fluency or the total amount of time spent on revising papers was also addressed. It could be that the greater number and variety of errors that appear using unfocused peer and instructor CF simply forced students to spend a greater amount of time on their writing, which in turn resulted in better compositions. 


\section{References}

Chandler, Jean. 2003. The efficacy of various kinds of error feedback for improvement in the accuracy and fluency of L2 student writing. Journal of Second Language Writing 12(3). 267-296.

Colpitts, Bradley D. F. 2016. Japanese Students' Perceptions of Peer Corrective Feedback in an EFL Classroom. Acta Humanistica Et Scientifica Universitatis Sangio Kyotiensis 49. 345-358.

Diab, Nuwar M. 2016. A comparison of peer, teacher and self-feedback on the reduction of language errors in student essays. System 57. 55-65.

Ellis, Rod. 2002. Does form-focused instruction affect the acquisition of implicit knowledge? Studies in Second Language Acquisition 24(2). 223-236.

Ellis, Rod Sheen \& Younghee, Murakami Mihoko, \& Takashima, Hide. 2008. The effects of focused and unfocused written corrective feedback in an English as a foreign language context. System 36(3). 353-371.

Fazilatfar, Ali M. \& Fallah, Nader \& Hamavandi, Manoosh \& Rostamian, Morteza. 2014. The effect of unfocused written corrective feedback on syntactic and lexical complexity of L2 writing. Procedia-Social and Behavioral Sciences 98. 482-488.

Frear, David \& Chiu, Yi-hui. 2015. The effect of focused and unfocused indirect written corrective feedback on EFL learners' accuracy in new pieces of writing. System 53. 24-34.

Ghazi, Sara \& Zamanian, Mostafa. 2016. The effect of asynchronous versus conventional corrective feedback on the correct use of prepositions in an EFL context. International Journal of Language and Communication 5(2). 152.

Hosseiny, Manijeh. 2014. The role of direct and indirect written corrective feedback in improving Iranian EFL students' writing skill. Procedia-Social and Behavioral Sciences 98. 668-674.

Hyland, Ken. 2003. Second Language Writing. New York, NY: Cambridge University Press.

Jokar, Mohammad \& Soyoof, Ali. 2014. The influence of written corrective feedback on two Iranian learners' grammatical accuracy. Procedia-Social and Behavioral Sciences 98. 799-805.

Kazemipour, Salva. 2014. Comparing the outcomes of two types of corrective feedback on EFL classes' final exam. Procedia-Social and Behavioral Sciences 98. 876-881.

Kwon, Hyunjeong \& Lee, Chung Hyun. 2011. Learner uptake of feedback in text-based synchronous computer mediated communication (SCMC). Multimedia Assisted Language Learning 14(2). 211-234.

Lyster, Roy \& Ranta, Leila. 1997. Corrective feedback and learner uptake: Negotiation of form in communicative classrooms. Studies in Second Language Acquisition 19(1). 37-66.

Scovel, Thomas. 1998. Psycholinguistics. Oxford: Oxford University Press.

Seiffedin, Ahmed H. \& El-Sakka, Samah M. F. 2017. The impact of direct-indirect corrective e-feedback on EFL students' writing accuracy. Theory and Practice in Language Studies 7(3). 166.

Storch, Neomy \& Wigglesworth, Gillian. 2010. Learners' processing, uptake, and retention of corrective feedback on writing. Studies in Second Language Acquisition 32. 303-334.

Swain, Merrill. 2005. The output hypothesis: Theory and research. In Hinkel, Eli (ed.), Handbook of research in second language teaching and learning, 471-483. New York: Routledge.

Swain, Merrill. 2008. The output hypothesis: Its history and future. Foreign Language Teaching and Research 40(1). 45-50.

Truscott, John. 1996. The case against grammar correction in L2 writing classes. Language Learning 46(2). 327-369.

Truscott, John \& Hsu, Angela Y. P. 2008. Error correction, revision, and learning. Journal of Second Language Writing 17(4). 292-305. 